\title{
COMPARATIVE ANTIFUNGAL ACTIVITY OF WILD AND CULTIVATED LEAVES OF FICUS CARICA LINN
}

\author{
Nangial Bashir Ullah', Wajid Ali', Bushra Iftikhar', Saud Azhar², Sunia Arif ${ }^{3}$, Sarwat Iftikhar', Samin Jan ${ }^{4}$ \\ ${ }^{1}$ Department of Community Medicine, Khyber Medical College, Peshawar - Pakistan \\ ${ }^{2} 4^{\mathrm{TH}}$ Year MBBS, Khyber Medical Colleg, Peshawar - Pakistan \\ ${ }^{3}$ Department of Pathology, Khyber Medical College, Peshawar - Pakistan \\ ${ }^{4}$ Department of Botany, Islamia College, Peshawar - Pakistan
}

\begin{abstract}
Objective: The aim of this study was to compare the antifungal activity of wild and cultivated Ficuscarica Linn leaves extract.

Material and Methods: A cross-sectional analytic study was conducted in the Department of Botany Islamia College Peshawar from June 2016 to December 2016. After taking Permission from Botany department samples of two different species of wild and cultivated Ficus Carina plant were taken and analyzed for antifungal activity.

Results: Comparison of Zone of Inhibition in both Aspergillus niger and Aspergillus fumigatus colonies revealed that cultivated species of Ficuscarica Linn had more antifungal property against both the fungal species (63\% and higher compared that to wild species having a maximum zone of inhibition of 54.54\%), except for wild plant extract in the polar solvent such as chloroform which had a high level of antifungal activity (61.53\%) only against Aspergillus fumigatus. The experiment also revealed that extracts from both wild and cultivated Ficuscarica Linn leaves in polar solvents such as methanol and chloroform showed a higher level of antifungal activity against both the fungal species compared to extract taken in non-polar solvents.
\end{abstract}

Conclusion: Extract from cultivated species of Ficuscarica Linn had a higher level of activity against both the fungal species i.e. Aspergillus niger and Aspergillus fumigatus, especially extract taken in polar solvents.

Key Words: Ficuscarica Linn, antifungal, tube dilution, zone of inhibition.

This article may be cited as: Ullah NB, Ali W, Iftikhar B, Azhar S, Arif S, Iftikhar S, Jan S. Comparative antifungal activity of wild and cultivated leaves of ficus carica linn. J Med Sci 2021 July;29(3):104-107

\section{INTRODUCTION}

Pakistan's wide and diverse geological and climatic spectrum offers ecosystems to a very wide variety of plants. Many of these species have a pivotal role in medicine. According to a general survey of Pakistan about 6000 species of flowering plants exist in the country, out of which 600-700 are of medicinally important species ${ }^{1}$. Most local botanists believe this number of medicinally important plants to be an underestimation due to lack of research and effort. According to the drug bank statistics, there are a total of 14,315 drugs while the FDA reports the total number of prescription drugs to be over 20,000 . About 85,000 valuable medicinal plant species are reported worldwide ${ }^{2}$. Given this information, one can infer that there is a lot more to plants to be used as medicines than human imagination. The history of plants to be utilized as medicines is rather

\section{Correspondence}

\section{Dr. Wajid Ali}

Department of Biochemist Khyber Medical College, Peshawar - Pakistan

Email: sweetwajidali@yahoo.com

Cell: +92-333-5922908

Date received: $02-03-2021$

Date revised: $\quad 21-08-2021$

Date accepted: $07-09-2021$ ancient ${ }^{3}$. These plant materials initially took the form of crude drugs such as poultices, teas, powders, tinctures and many other herbal formulations. Not so long ago, it was discovered that the medicinal properties of plants are due to their active chemical compounds which produce a definite physiological action on the human body and the isolation of active compounds such as morphine from opium in the early 19th century made a revolutionary milestone in the history of medicine ${ }^{4}$. Since the earliest isolation of active ingredients from different plants, many essential drugs have been isolated such as aspirin from Salix alba, digoxin from Digitalis purpurea, quinine from Cinchona officinalis, atropine from Atropa belladonna and many other important drugs without which modern medicine would be obsolete. The most important of these bioactive constituents of plants are alkaloids, tannins, flavonoids and phenolic compounds. In the modern world use of plants in allopathic and homoeopathic medicine is an important component of the health care system in different countries of the world ${ }^{5}$. German herbal medicines constitute a fathomable example to help laymen understand the wide utility of plants as medicines. Thus, the utility of plants in pharmaceuticals for prevention, treatment and controlling different diseases needs no introduction but a brief discussion and mention reminds 
humankind of its utmost importance ${ }^{6}$. From being used as an additive to foods meant for pregnant women and nursing mothers for medicinal purposes to treat life-threatening infections due to antibiotic properties, the utility of plants in both traditional and modern medicine cannot be emphasized enough ${ }^{7}$. It has been observed through many studies that in developing countries there has been an increased shift towards the use of medicinal plants as therapeutic agents in comparison with pharmaceutical drugs. Although mass psychology and firm belief in the potential benefits of medicinal plants and their by-products might be a contributory factor in some developing communities which is mainly passed down through generations, alternative and complementary therapies based on plant remedies are getting popular by the day and even allopathic healthcare professionals in developed countries do not deny their role in treatment and prevention ${ }^{8}$. Safety and drug interaction regarding the usage of plants for medicinal purposes often raise a concern in people who go by the book and are not well versed in botany and biochemistry. Another group that shares and supports the congruent belief due to monopoly and monetary reasons are the pharmaceutical companies that make branded biochemical drugs. But the modern unbiased world is accepting the potential that plants offer in terms of therapeutic use ${ }^{9}$. Many of the plant-based medicines are now Food and Drug Administration (FDA) approved ensuring their quality and safety along with mentioning possible drug interactions. One important property of plants that have led to their use throughout history is their ability to kill bacteria, protozoa, viruses, fungi, animals and other unicellular and multicellular organisms. This property is often used and manipulated in a dexterous way by nature and by humans fit and beneficial to their needs. Many researchers have examined long-established uses of medicinal plants, but only a few studies have led to these ethnobotanical findings with laboratory jobs to confirm the real antimicrobial property of this plants ${ }^{10}$. Our study is an effort to contribute towards the authenticity of the activity in a specific plant species.

The rationale behind conducting this study is to find the antifungal activity of the fore mentioned plants. As pharmaceutical drugs have a lot of side effects, therefore, the need is to find benefits hidden in medicinal plants which are natural and have negligible side effects.

\section{MATERIALS AND METHODS}

This cross-sectional analytic study was conducted in the Department of Botany Islamia College Peshawar from June 2018 to December 2019. One sample of each variety of FICUS CARICA LINN wild and cultivated was taken and analyzed its chemical components were against antifungal properties. The agar tube dilution method was used as an antifungal assay to demonstrate the antifungal activity of the extract. The following fungal strains were used in this study:

\section{Aspergillusniger.}

Aspergillus fumigatus

Each strain was maintained on a Sabouraud dextrose agar (SDA) medium at room temperature.

The composition of Sabouraud dextrose agar medium was: Peptone complex $10 \mathrm{mg} / \mathrm{ml}$

\section{Glucose $40 \mathrm{mg} / \mathrm{ml}$}

Agar $15 \mathrm{mg} / \mathrm{ml}$

The samples for antifungal assay were prepared from an initial stock of $15 \mathrm{mg}$ of each plant extract sample per $10 \mathrm{ml}$ of Dimethyl Sulfoxide (DMSO). Slant cultures without extract were used for negative control. Data were analyzed using SPSS version 21.

\section{LABORATORY PROCEDURE:}

Media for fungus was prepared by dissolving $6.5 \mathrm{mg}$ of Sabouraud dextrose agar in $100 \mathrm{mldistilled} \mathrm{water} \mathrm{with}$ the $\mathrm{pH}$ adjusted to 5.6. Test tubes were marked to $13 \mathrm{~cm}$ mark. Sabouraud dextrose agar (commercial MERCK) was dispensed as $4 \mathrm{ml}$ volume into screw-capped tubes or cotton plugged test tubes and the test tubes were autoclaved at $1210 \mathrm{C}$ for 20 minutes. The only single concentration of $15 \mathrm{mg} / 10 \mathrm{ml}$ was made. Tubes were allowed to cool at 500 $\mathrm{C}$ and non-solidified Sabouraud dextrose agar was loaded with $100 \mu \mathrm{l}$ of $15 \mathrm{mg} / \mathrm{ml}$ plant extract which was inserted by compound pipette from the stock solution. Tubes were then allowed to solidify in a slant position at room temperature.

One slant of the extracted sample was prepared for each fungal species. The tubes containing solidified media and test compound were inoculated with a $4 \mathrm{~mm}$ diameter piece of inoculum, taken from the seven-day-old culture of the fungi. Negative control test tubes without extract were also inoculated. The test tubes were incubated for 7 days at $280 \mathrm{C}$. Cultures were examined twice weekly during the incubation. Reading was taken by measuring the linear length of fungus in a slant position. Growth inhibition was calculated with reference to the negative control. Percentage inhibition of fungus growth for each concentration of compound was calculated by the following formula Percentage inhibition of fungal growth $=100$ - Linear growth in test tube $(\mathrm{mm}) \times 100$ Liner growth in control $(\mathrm{mm})$

\section{RESULTS}

Antifungal activity of extracts from leaves of cultivated and wild species of Ficuscarica Linn against Aspergillus niger and Aspergillus fumigatus.

\section{DISCUSSION}

Our study was an attempt to demonstrate the medicinal value of Ficuscarica Linn and to demonstrate its antifungal activity. A local study conducted in 2013 , which contrasts with our study revealed that neither bark nor 
Table 1: Antifungal activity of extracts from leaves of cultivated and wild species of Ficuscarica Linn against Aspergillus niger and Aspergillus fumigatus.

\begin{tabular}{|c|c|c|c|c|c|}
\hline Organism Organism & Plant Ficuscarica Linn & Leaves Extract & L.G.C(mm) & L.G.T(mm) & \%Inhibition \\
\hline \multirow[t]{4}{*}{ Aspergillusniger } & \multirow[t]{4}{*}{ Cultivated Species } & Methanol & 110 & 70 & $63.63 \%$ \\
\hline & & Chloroform & 110 & 60 & $54.54 \%$ \\
\hline & & n-hexane & 110 & 45 & $40.90 \%$ \\
\hline & & Ethyl acetate & 110 & 50 & $45.45 \%$ \\
\hline \multirow{4}{*}{$\begin{array}{l}\text { Aspergillus } \\
\text { fumigatus }\end{array}$} & \multirow[t]{4}{*}{ Cultivated Species } & Methanol & 130 & 85 & $65.38 \%$ \\
\hline & & Chloroform & 130 & 70 & $53.48 \%$ \\
\hline & & n-hexane & 130 & 30 & $23.07 \%$ \\
\hline & & Ethyl acetate & 130 & 25 & $19.23 \%$ \\
\hline \multirow{4}{*}{$\begin{array}{l}\text { Aspergillus } \\
\text { niger }\end{array}$} & \multirow[t]{4}{*}{ Wild species } & Methanol & 110 & 60 & $54.54 \%$ \\
\hline & & Chloroform & 110 & 45 & $40.90 \%$ \\
\hline & & n-hexane & 110 & 30 & $27.27 \%$ \\
\hline & & Ethyl acetate & 110 & 20 & $18.18 \%$ \\
\hline \multirow[t]{4}{*}{ Aspergillus fumigatus } & \multirow[t]{4}{*}{ Wild species } & Methanol & 130 & 70 & $53.84 \%$ \\
\hline & & Chloroform & 130 & 80 & $61.53 \%$ \\
\hline & & n-hexane & 130 & 40 & $30.76 \%$ \\
\hline & & Ethyl acetate & 130 & 25 & $19.23 \%$ \\
\hline
\end{tabular}

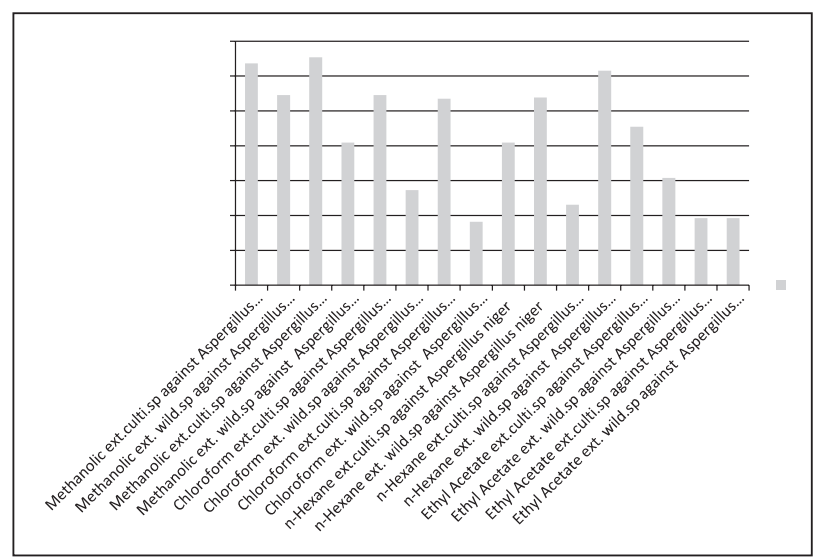

Fig 1: Comparison of Zone of Inhibition (\%) of extracts from leaves of cultivated and wild species of Ficuscarica Linn against Aspergillus Niger and Aspergillus fumigates in methanolic (alternatively known as methanol), chloroform, n-hexane and ethyl acetate

leaves of Ficuscarica Linn had any antifungal potentials ${ }^{11}$. One of the possible explanations could be that they used a very potent antifungal drug (amphotericin B) as the standard/control in agar culture which was able to mask even the minute antifungal effect from fig extracts. Another possibility could be the chemical nature of one of the two solvents in which the extract from the plant was taken. The extracts of the four Ficus species had significant antibacterial activity in a study in Egypt but no antifungal activity was demonstrated in their study ${ }^{12}$. In contrast to this study, our study demonstrated antifungal activity. Although the four Ficus species did not include the Ficuscarica Linn species of the Ficus genus in the research, the antibacterial property was demonstrated in other studies. Similarly, a study in an Indian journal showed that Ficuscarica was rich in phytochemicals such as flavonoids, alkaloids and saponins ${ }^{13}$. Most of the antimicrobial activity was attributed to flavonoids. This study lacked any information regarding antifungal property due to a lack of sufficient evidence as fungal species were not used in the experiment. Likewise, a study in Morocco reinforced the antimicrobial, antitumor, antioxidant and antipyretic activity of Ficuscarica but the antifungal property was not included in the experiment ${ }^{14}$

A study conducted in Malaysia used the same types of solvents for sample preparations as was used in our study Ficuscarica had antifungal properties against seven fungal strains using disc diffusion method ${ }^{15}$. One noteworthy finding in their study was that Ficuscarica had wiped out one of the fungal population Candida albicans. A similar study conducted in Baghdad showed antifungal activity of Ficuscarica against three fungal strains and the same measure of the zone of inhibition was used as ours ${ }^{16}$. Another study conducted on Ficuscarica leaves revealed that the antifungal property of plants extracts from the Ficus genus was mainly due to the chitinases and chitinase like enzymes and antifungal activity was witnessed against Saccharomyces cerevisiae in the experiment ${ }^{17}$. There was an attempt to isolate two proteins from Ficuscarica in another study which proved that those two proteins had potent antifungal activity against six fungal strains used in the experiment and similar inhibitory zone measurements were taken as our study ${ }^{18}$.

\section{CONCLUSION}

It is concluded that fig exhibits antifungal activity against a wide variety of fungal strains, signifying that fig 
may indeed be used as a naturally occurring broad-spectrum antifungal drug. Moreover, what has come to the limelight in the study was that cultivated and domesticated fig has more to offer as an antifungal agent compared to wild fig.

\section{LIMITATIONS}

The shortcoming of the research was that we could not compare the findings with other studies showing the antifungal potential of Ficuscarica due to experimental differences. The differing nature of solvents, fungal strains, temperatures, exposure times, concentrations, units of measurements, parts of the Ficuscarica plant used limits us to compare the exact antifungal potency. We are, however, confident through findings in our study that antifungal property exists in Ficuscarica and the use of common fig as an antifungal agent can be compared to synthetic antifungal drugs, thus proving its health benefits scientifically and justifying the historical and ancestral use of this plant and its fruit for medicinal purposes.

\section{REFERENCES}

1. Sharif A, Asif $H$, Younis W, Riaz $H$, Bukhari IA, Assiri AM. Indigenous medicinal plants of Pakistan used to treat skin diseases: a review. Chinese medicine. 2018 Dec;13(1):1-26.

2. Devi K, Karthikai GD, Thirumaran G, Arumugam R, Anantharaman P. Antibacterial activity of selected medicinal plants from Parangipettai coastal regions; Southeast coast of India. Acad. J. Plant Sci. 2010;3:122-5.

3. Liu Y, Wang MW. Botanical drugs: challenges and opportunities: contribution to Linnaeus Memorial Symposium 2007. Life Sciences. 2008 Feb 27;82(9-10):445-9.

4. Hosseinzadeh S, Jafarikukhdan A, Hosseini A, Armand $R$. The application of medicinal plants in traditional and modern medicine: a review of Thymus vulgaris. International J Clin Med. 2015;6(09):635.

5. DEB D, Datta BK, DEBBARMA J, DEB S. Ethno-medicinal plants used for herbal medication of jaundice by the indigenous community of Tripura, India. Biodiversitas J Biolog Diversity. 2016;17(1).

6. Joshee N, Dhekney SA, Parajuli P, editors. Medicinal Plants: From Farm to Pharmacy. Springer Nature; 2019 Nov 11.

7. Sofowora A, Ogunbodede E, Onayade A. The role and place of medicinal plants in the strategies for disease prevention. African $\mathrm{J}$ tradit, complementary and alternative med. 2013 Aug 14;10(5):210-29.

8. Jamshidi-Kia F, Lorigooini Z, Amini-Khoei H. Medicinal plants: Past history and future perspective. $\mathrm{J}$ herb med pharma . 2018;7(1).

9. Weli AM, Al-Salmi S, Al Hoqani H, Hossain MA. Biological and phytochemical studies of different leaves extracts of Pteropyrum scoparium. Beni-Suef University $\mathrm{J}$ basic and applied sci. 2018 Dec 1;7(4):481-6.

10. Bhattarai S, Chaudhary RP, Taylor RS, Ghimire SK. Biological Activities of some Nepalese Medicinal Plants used in treating bacterial infections in Human beings Nepal J Sci and Tech. 2009;10:83-90.

11. Khakurel B, Pradhan R, Lakhey PB. A preliminary screening of some Nepalese medicinal plants for antimicrobial activity. Plant Resources. 2014 Apr;36:72-5.

12. Azam FA, Qadir MI, Uzair M, Ahmad B. Evaluation of antibacterial and antifungal activity of Ficuscarica and Cassia fistula. Lat. Am. J. Pharm. 2013 Jan 1;32(9):1412-4.

13. Mousa O, Vuorela P, Kiviranta J, Törnquist K, Vuorela H, Hiltunen R. Bioactivity of certain Egyptian Ficus species. Planta Medica. 1992 Dec;58(S 1):632-3.

14. Soni N, Mehta S, Satpathy G, Gupta RK. Estimation of nutritional, phytochemical, antioxidant and antibacterial activity of dried fig (Ficuscarica). J Pharma and Phytochemistry. 2014 Jul 1;3(2).

15. Bouyahya A, Bensaid M, Bakri Y, Dakka N. Phytochemistry and ethno pharmacology of Ficuscarica. Int $\mathrm{J}$ Biochem Res Rev. 2016;14:1-2.

16. Mawa S, Husain K, Jantan I. Ficuscarica L.(Moraceae): Phytochemistry, traditional uses and biological activities. Evidence-Based Complementary and Alternative Medicine. 2013 Jan 1;2013.

17. Rashid KI, Mahdi NM, Alwan MA, Khalid LB. Antimicrobial activity of fig (Ficuscarica Linn.) leaf extract as compared with latex extract against selected bacteria and fungi. J Babylon University/Pure and Applied Sciences. 2014;5(22):1620-6.

18. Raskovic B, Lazic J, Polovic N. Characterisation of general proteolytic, milk clotting and antifungal activity of Ficuscarica latex during fruit ripening. $\mathrm{J}$ Sci of Food and Agriculture. 2016 Jan 30;96(2):576-82.

CONFLICT OF INTEREST: Authors declare no conflict of interest

GRANT SUPPORT AND FINANCIAL DISCLOSURE: NIL

\section{AUTHOR'S CONTRIBUTION}

Following authors have made substantial contributions to the manuscript as under

Ullah NB: Data analysis, Manuscript Writing and Literature Review

Ali W: Data collection

Iftikhar B: Supervision and Review

Azhar S: $\quad$ Manuscript Writing

Arif S: Literature Review

ifitikhar S: Data analysis and literature review

Jan S: Data Collection

Authors agree to be accountable for all aspects of the work in ensuring that questions related to the accuracy or integrity of any part of the work are appropriately investigated and resolved. 